\title{
Pulmonary function of patients with 2019 novel coronavirus induced-pneumonia: a retrospective cohort study
}

\author{
Dongqing Lv ${ }^{1 \# \wedge}$, Xi Chen ${ }^{1 \#}$, Xiaodan Wang ${ }^{1}$, Linghong Mao ${ }^{1}$, Jiao Sun ${ }^{1}$, Guixian Wu ${ }^{1}$, Zhi Lin ${ }^{1}$, \\ Ronghai Lin ${ }^{2}$, Jiansong $\mathrm{Yu}^{3}$, Xiaomai $\mathrm{Wu}^{1}$, Yongpo Jiang ${ }^{2 \wedge}$
}

${ }^{1}$ Department of Respiratory Medicine, Taizhou Hospital of Zhejiang Province Affiliated to Wenzhou Medical University, Taizhou, China; ${ }^{2}$ Department of Critical Care Medicine, Taizhou Hospital of Zhejiang Province Affiliated to Wenzhou Medical University, Taizhou, China; ${ }^{3}$ Department of Rehabilitation Medicine, Taizhou Hospital of Zhejiang Province Affiliated to Wenzhou Medical University, Taizhou, China Contributions: (I) Conception and design: D Lv, Y Jiang; (II) Administrative support: R Lin; (III) Provision of study materials or patients: X Wu ; (IV) Collection and assembly of data: X Chen, L Mao, J Sun, Z Lin, G Wu, J Yu; (V) Data analysis and interpretation: Y Jiang, R Lin; (VI) Manuscript writing: All authors; (VII) Final approval of manuscript: All authors.

\#These authors contributed equally to this work.

Correspondence to: Xiaomai Wu, MD; Ronghai Lin, MD; Yongpo Jiang, MD. Taizhou Hospital of Zhejiang Province Affiliated to Wenzhou Medical University, No. 150, Ximen Street, Taizhou, China. Email: wuxm@enzemed.com; linrh@enzemed.com; 7719@enzemed.com.

Background: The aim of this study was to investigate the pulmonary function of patients with 2019 novel coronavirus (COVID-19)-induced pneumonia.

Methods: A retrospective analysis of 137 patients with COVID-19-induced pneumonia who were discharged from the Enze Hospital, Taizhou Enze Medical Center (Group) from January 312020 to March 112020 was conducted. Follow-up occurred 2 weeks after hospital discharge, during which patients underwent a pulmonary function test.

Results: Of the 137 patients who underwent a pulmonary function test 2 weeks after discharge, $51.8 \%$ were male, and the mean age was 47 years. Only $19.7 \%$ of the patients were identified as having severe COVID19-induced pneumonia. The pulmonary function tests showed that for a small number of patients the forced expiratory volume in one second/forced vital capacity ratio (FEV1/FVC)/\% values were $<70 \%$, and the mean forced inspiratory volume (IVC) and FVC values were $2.4 \pm 0.7$ and $3.2 \pm 0.8 \mathrm{~L}$, respectively. In severe cases, $88.9 \%$ of patients had an IVC $<80 \%$ of the predicted value, and $55.6 \%$ of patients had an $\mathrm{FVC}<80 \%$ of the predicted value. The proportion of patients with maximum expiratory flow rate at $25 \%, 50 \%$ and $75 \%$ of the vital capacity (MEF25, MEF50, and MEF75) values <70\% were 55.6\%, 40.7\%, and 25.9\%, respectively. In the non-severe group, $79.1 \%$ of patients had an IVC $<80 \%$ of the predicted value, and $16.4 \%$ of patients had an FVC $<80 \%$ of the predicted value. The mean MEF25, MEF50, and MEF75 $<70 \%$ values were $57.3 \%$, $30 \%$, and $13.6 \%$, respectively.

Conclusions: Our results demonstrated that the pulmonary function of patients with COVID-19-induced pneumonia predominantly manifested as restrictive ventilation disorder and small airway obstruction, which was increased in critically ill patients.

Keywords: COVID-19-infected pneumonia; pulmonary fibrosis; pulmonary function; restrictive ventilation disorder

Submitted Aug 07, 2020. Accepted for publication Sep 11, 2020.

doi: 10.21037/apm-20-1688

View this article at: http://dx.doi.org/10.21037/apm-20-1688

^ ORCID: Dongqing Lv, 0000-0001-8226-9596; Yongpo Jiang, 0000-0002-5681-3663. 


\section{Introduction}

The 2019 novel coronavirus (COVID-19) is a viral infectious disease that is now a widespread concern (1-3). The most severe symptom of COVID-19 is severe acute respiratory distress syndrome, which can lead to rapid death (1). Significant injury to type II alveolar epithelial cells induces pulmonary fibrosis through cytokine storm and immunopathology (4). Pulmonary fibrotic changes are occasionally observed in response to viral infections, and can manifest as a consequence of several respiratory viral infections, such as Middle East respiratory syndrome (MERS) and avian influenza (5). In particular, in the 2003 epidemic of severe acute respiratory syndrome (SARS), it was observed that many patients who survived the severe illness developed residual pulmonary fibrosis, with increased severity seen in older patients (6). Varying degrees of fibrosis have also been observed in autopsies of fatal COVID-19 cases (7). In the later period of COVID-19induced illness, the infection predominantly manifests as organized pneumonia and fibrosis in clinical findings and radiography (8). Despite these observations, the pulmonary function of patients with COVID-19-induced pneumonia has not yet been reported on. The purpose of this study was to investigate pulmonary function and treatment strategies for patients with COVID-19-induced pneumonia. We present the following article in accordance with the STROBE reporting checklist (available at http://dx.doi. org/10.21037/apm-20-1688).

\section{Methods}

\section{Study design and patients}

This was a retrospective, observational, single-center study. The study was registered in the Chinese Clinical Trial Registry (ChiCTR2000029866). The study was conducted in accordance with the Declaration of Helsinki (as revised in 2013). Ethics approval was granted by the Hospital Ethics Committee of Enze Hospital of Taizhou Enze Medical Center (Group). Patients with laboratoryconfirmed COVID-19 who improved and were discharged were consecutively included. Written informed consent was obtained from all participants before inclusion.

The diagnostic criteria was based on laboratory (nucleic acid)-confirmed infection with COVID-19 and lung involvement confirmed by chest imaging. The discharge criteria included the following: (I) temperature returned to normal for at least 3 days; (II) significant improvements in respiratory symptoms; (III) an imaging study showed significant lung inflammatory uptake; (IV) two consecutive COVID-19-negative respiratory pathogen nucleic acid detection results (sampling time interval of at least 1 day). Patients were excluded if they were pregnant. The diagnostic criteria for severe patients were as follows: (I) respiratory distress [respiratory rate $(\mathrm{RR})>30$ breaths/ min at rest]; (II) mean oxygen saturation $\leq 93 \%$; arterial oxygen pressure/oxygen concentration $\left(\mathrm{PaO}_{2} / \mathrm{FiO}_{2}\right) \leq 300$ $\mathrm{mmHg}$; (III) chest imaging lesion progression $>50 \%$ within 24-48 hours (9).

\section{Pulmonary function test}

The pulmonary ventilation function test was performed in accordance with the operating instructions for the American Thoracic Association pulmonary function test via an automatic pulmonary function testing system (made in Germany) (10). Testing parameters included forced expiratory volume in the first second $\left(\mathrm{FEV}_{1}\right)$, forced inspiratory volume (IVC), forced expiratory volume in the first second as a percentage of the expected value $\left(\mathrm{FEV}_{1} /\right.$ IVC), maximum expiratory volume at $75 \%$ of the vital capacity airflow rate (MEF75), maximum expiratory flow rate at $50 \%$ of the vital capacity (MEF50), and maximum expiratory flow rate at $25 \%$ of the vital capacity (MEF25). Each test was repeated 3 times, and the most standard waveform were used. $\mathrm{FEV}_{1} / \mathrm{FVC}<70 \%$ was defined as obstructive ventilation dysfunction, FVC or IVC $<80 \%$ of the predicted value indicated restrictive ventilation dysfunction, and a value of $<70 \%$ of the predicted value defined impaired MEF $25-75 \%$ values.

\section{Data collection}

All patient data were extracted from electronic medical records and included age, sex, smoking history, chronic obstructive pulmonary disease history and pulmonary function measures. The last follow-up was completed on 25 March 2020. Chest computed tomography (CT) was used for the imaging analysis.

\section{Statistical methods}

Data are expressed as the mean \pm standard deviation (SD), median with interquartile range or percent with number of patients. Normality was evaluated by using the ShapiroWilk test $(\mathrm{P}$ value $>0.05)$. Comparisons between groups 
Table 1 Baseline characteristics and pulmonary function items of 137 patients with COVID-19

\begin{tabular}{|c|c|c|c|c|}
\hline Characteristics & All patients $(\mathrm{N}=137)$ & Non-severe $(\mathrm{N}=110)$ & Severe $(N=27)$ & $\mathrm{P}^{\mathrm{a}}$ \\
\hline Age (year), mean \pm SD & $47 \pm 13$ & $46 \pm 13$ & $52 \pm 12$ & 0.018 \\
\hline Male sex, $\mathrm{n}(\%)$ & $71 / 137(51.8 \%)$ & $55 / 110(50.0 \%)$ & $16 / 27(59.3 \%)$ & 0.388 \\
\hline Smoking history, n (\%) & $6 / 137(4.4 \%)$ & $5 / 110(5.5 \%)$ & $1 / 27(3.7 \%)$ & 1.000 \\
\hline Chronic obstructive pulmonary disease, $\mathrm{n}(\%)$ & $2 / 137(1.5 \%)$ & $2 / 110(1.8 \%)$ & 0 & NA \\
\hline \multicolumn{5}{|l|}{ Pulmonary function } \\
\hline IVC/L & $2.4 \pm 0.7$ & $2.5 \pm 0.7$ & $2.1 \pm 0.6$ & 0.003 \\
\hline $\mathrm{FVC/L}$ & $3.2 \pm 0.8$ & $3.2 \pm 0.7$ & $2.7 \pm 0.8$ & 0.000 \\
\hline $\mathrm{FEV}_{1} / \mathrm{L}$ & $2.6 \pm 0.7$ & $2.7 \pm 0.6$ & $2.2 \pm 0.7$ & 0.001 \\
\hline$\left(\mathrm{FEV}_{1} / \mathrm{FVC}\right) / \%$ & $82.7 \pm 7.4$ & $83.1 \pm 7.3$ & $81.4 \pm 7.9$ & 0.527 \\
\hline MEF25 & $1.2 \pm 0.6$ & $1.2 \pm 0.6$ & $1.1 \pm 0.6$ & 0.266 \\
\hline MEF50 & $3.6 \pm 1.3$ & $3.6 \pm 1.2$ & $3.2 \pm 1.6$ & 0.084 \\
\hline MEF75 & $6.0 \pm 1.9$ & $6.1 \pm 1.8$ & $5.3 \pm 2.2$ & 0.061 \\
\hline MEF75-85 & $6.1 \pm 2.1$ & $6.3 \pm 2.0$ & $5.4 \pm 2.3$ & 0.065 \\
\hline PEF & $6.6 \pm 2.2$ & $6.8 \pm 2.1$ & $6.1 \pm 2.3$ & 0.117 \\
\hline
\end{tabular}

${ }^{\mathrm{a}}, \chi^{2}$ test, Fisher's exact test, Student's $t$-test and Mann-Whitney U Test. IVC, forced inspiratory volume; FVC, forced vital capacity; FEV1, forced expiratory volume in the first second; MEF75, maximum expiratory volume at $75 \%$ vital capacity; MEF50, maximum expiratory flow rate at $50 \%$ vital capacity; MEF25, maximum expiratory flow rate at $25 \%$ vital capacity; MEF $75-85$, maximum expiratory flow rate at 75-85\% vital capacity; PEF, peak expiratory flow.

of continuous variables, which were normally distributed, were carried out using Student's $t$-test or a corrected $t$ test. Comparisons of other scenarios were performed using the Mann-Whitney $U$ test. Comparisons of categorical variables were performed using the $\chi^{2}$ test or Fisher's exact test. $\mathrm{P}$ values $<0.05$ were considered significant. All statistical analyses were performed with SPSS 26.0.

\section{Results}

A total of 137 patients with COVID-19 underwent pulmonary function tests 2 weeks after hospital discharge. All patients were included in the analysis and no patients were lost to follow-up for 2 weeks. No patients used ventilator or extracorporeal membrane oxygenation (ECMO). The mean age was 47 years, and $51.8 \%$ were male. Among all patients, 6 patients (4.4\%) had a smoking habit, and $2(1.5 \%)$ patients had a history of chronic obstructive pulmonary disease (COPD) (Table 1). The IVC and $\mathrm{FVC}$ values were significantly reduced in severe cases compared to mild cases $(\mathrm{P}<0.05)$, and the mean IVC and FVC values were $2.4 \pm 0.7$. The $\left(\mathrm{FEV}_{1} / \mathrm{FVC}\right) \%$ value was

\section{$82.7 \% \pm 7.4 \%$ (Table 1 ).}

Furthermore, $81.0 \%$ of patients had an IVC $<80 \%$ of the predicted value, and $24.1 \%$ of patients had an $\mathrm{FVC}<80 \%$ of the predicted value. In severe cases, $88.9 \%$ of patients had an IVC $<80 \%$ of the predicted value, and $55.6 \%$ of patients had an $\mathrm{FVC}<80 \%$ of the predicted value. The proportion of patients with MEF25, MEF50, and MEF $75<70 \%$ values were $55.6 \%, 40.7 \%$, and $25.9 \%$, respectively. In the nonsevere group, $79.1 \%$ of patients had an IVC $<80 \%$ of the predicted value, and $16.4 \%$ of patients had an FVC $<80 \%$ of the predicted value. The mean MEF 25, MEF50, and MEF75 < $70 \%$ values were $57.3 \%, 30 \%$, and $13.6 \%$, respectively, indicating small airway dysfunction (Figure 1).

\section{Discussion}

Approximately 200 million people develop viral pneumonia worldwide each year (11). In the past 10 years, this has been exacerbated by the addition of SARS, avian influenza virus (H1N1 and H7N9) and MERS outbreaks (12-14). In patients with viral pneumonia, post-acute respiratory distress syndrome (ARDS) pulmonary fibrosis and 
A
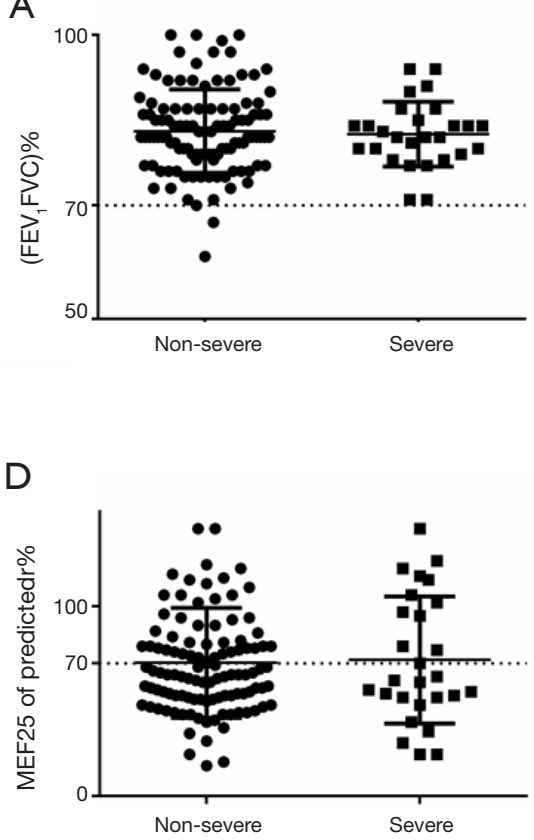

B

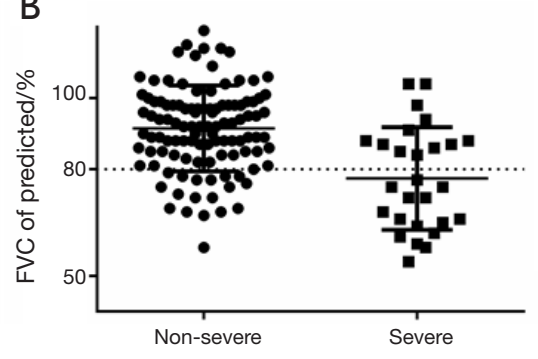

$E$

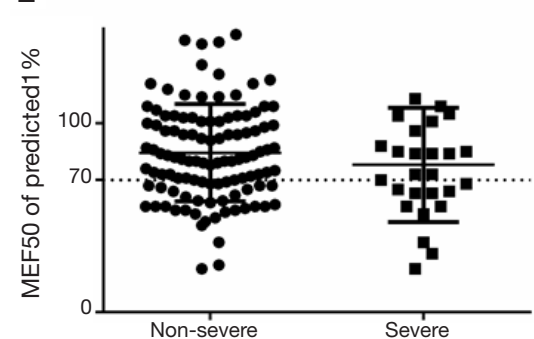

C

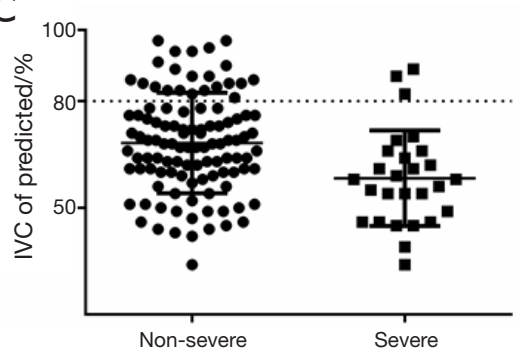

$\mathrm{F}$

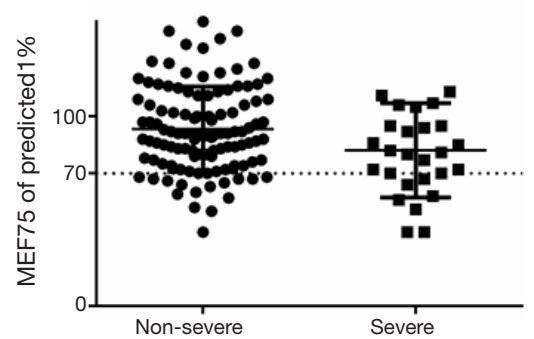

Figure 1 Pulmonary function parameters according to patient severity. (A) Only two patients $\left(\mathrm{FEV}_{1} / \mathrm{FVC}\right) / \%<70 \%$. The mean (FEV $/$ FVC) $\%>70 \%$; (B) $24.1 \%$ of patients had an FVC $<80 \%$ of the predicted value; (C) $81.0 \%$ of patients had an IVC $<80 \%$ of the predicted

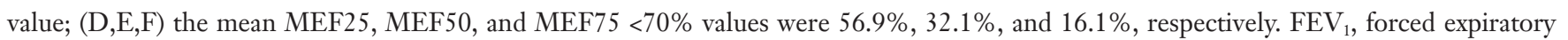
volume in the first second; IVC, forced inspiratory volume; FVC, forced vital capacity; MEF75, maximum expiratory volume at $75 \%$ vital capacity; MEF50, maximum expiratory flow rate at 50\% vital capacity; MEF25, maximum expiratory flow rate at 25\% vital capacity. FEV1, forced expiratory volume in the first second; IVC, forced inspiratory volume; FVC, forced vital capacity; MEF75, maximum expiratory volume at $75 \%$ vital capacity; MEF50, maximum expiratory flow rate at 50\% vital capacity; MEF 25 , maximum expiratory flow rate at $25 \%$ vital capacity.

pulmonary dysfunction are observed complications and the cause of pulmonary fibrosis is lung tissue inflammation damage, tissue structure destruction, fibroblast proliferation and a large amount of extracellular matrix accumulation (14). In long-term follow-up of patients, the rates of postARDS fibrosis and pulmonary dysfunction in patients with influenza are $10 \%$ and $54.2 \%$, respectively $(14,15)$. In this study, we found reduced IVC and FVC values in $81.0 \%$ of patients. Impaired MEF25-75\% values were indicative of small airway dysfunction (Figure 1). Our results showed that most patients displayed restrictive ventilatory dysfunction. Furthermore, the IVC decreases were greater than the FVC decreases, indicating that the virus is more harmful to the alveoli than the airways.

Preliminary evidence suggests that these lung function abnormalities improve over time (16). Recently, a study described the recovery of lung injury in SARS patients over the past 15 years (17). The results suggested that pulmonary function can be improved to a greater extent when the acute phase of infectious viral pneumonia is effectively managed. In this study, patients were followed up 2 weeks after hospital discharge. The rates of pulmonary dysfunction disorder were significant, and were consistent with the imaging results (Figure 2). However, a 2-week follow-up period is relatively short, and most patients' lung function and pulmonary fibrosis can be restored (17). These patients should continue to be monitored for any changes in condition and symptoms over a longer period.

Currently, there is no evidence-based medication for treating pulmonary fibrosis caused by viral pneumonia. Nintedanib is a tyrosine kinase inhibitor that is recommended for idiopathic pulmonary fibrosis (IFP). It exerts anti-pulmonary fibrosis activity by inhibiting fibroblast growth factor receptor (FGFR), platelet-derived growth factor receptor (PDGFR), and vascular endothelial growth factor receptor (VEGFR). Studies in mice found 

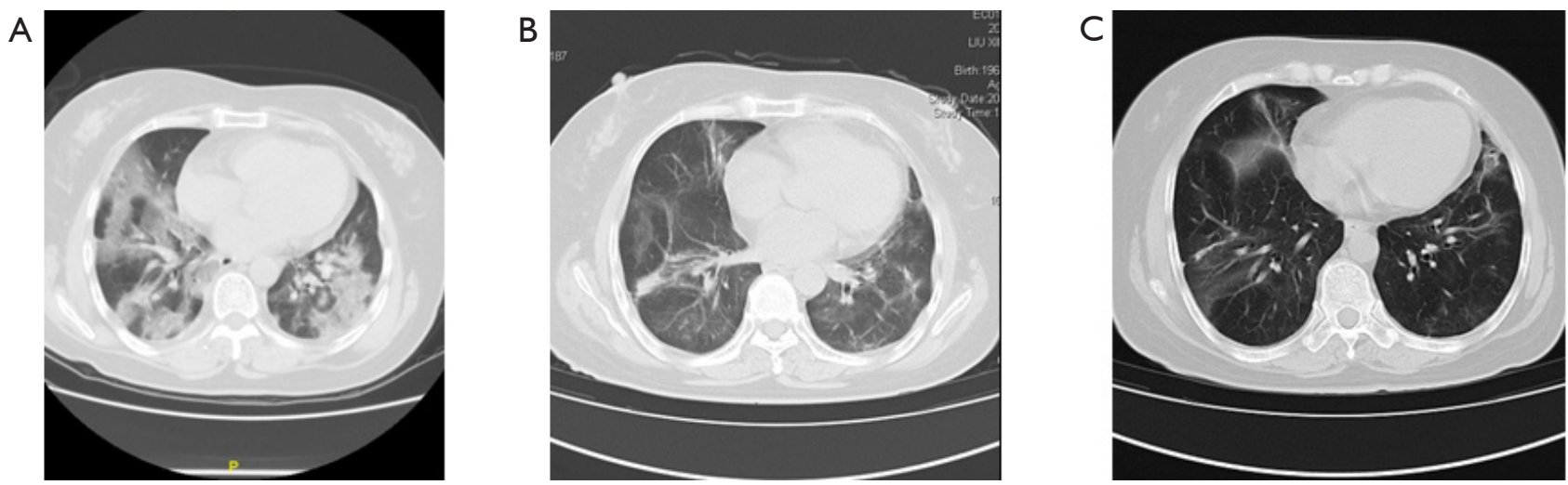

Figure 2 Chest computed tomography (CT) of a severe novel coronavirus pneumonia patient. Pulmonary fibrosis can be restored at 2 weeks after discharge. on admission (A), at discharge (B), and 2 weeks after discharge (C).

that nintedanib reduces high tidal volume mechanical ventilation-augmented epithelial mesenchymal transition and pulmonary fibrosis after bleomycin-induced acute lung injury (18). However, nintedanib has not been used in pulmonary fibrosis patients undergoing viral pneumonia treatment, warranting further clinical research. Moreover, pulmonary rehabilitation, such as breathing exercises and pulmonary function tests, is necessary for patients with pulmonary fibrosis caused by COVID-19-induced pneumonia. The limitation of the study is the samples were too small. Of course, we need a longer follow-up time to pay attention to the recovery of lung function in patients with COVID-19-induced pneumonia.

\section{Conclusions}

In summary, we found that the frequency of pulmonary dysfunction in patients with COVID-19-induced pneumonia is relatively high, manifesting as restrictive dysfunction and small airway injury. Our results highlight the need to pay close attention to pulmonary function and strengthen pulmonary function monitoring in these patients, and commence rehabilitation treatment if required.

\section{Acknowledgments}

The authors acknowledge all physicians and nurses at the Taizhou Public Health Center.

Funding: This study was funded by The Science and Technology Project of Taizhou (No. 1902ky02, 1902ky27); The Natural Science Foundation of Zhejiang Province
(Y20H150029).

\section{Footnote}

Reporting Checklist: The authors have completed the STROBE reporting checklist. Available at http://dx.doi. org/10.21037/apm-20-1688

Data Sharing Statement: Available at http://dx.doi. org/10.21037/apm-20-1688

Conflicts of Interest: All authors have completed the ICMJE uniform disclosure form (available at http://dx.doi. org/10.21037/apm-20-1688). The authors have no conflicts of interest to declare.

Ethical Statement: The authors are accountable for all aspects of the work in ensuring that questions related to the accuracy or integrity of any part of the work are appropriately investigated and resolved. The study was conducted in accordance with the Declaration of Helsinki (as revised in 2013). Ethics approval was granted by the Hospital Ethics Committee of Enze Hospital of Taizhou Enze Medical Center (Group) (No. K20200204). Written informed consent was obtained from all participants before inclusion.

Open Access Statement: This is an Open Access article distributed in accordance with the Creative Commons Attribution-NonCommercial-NoDerivs 4.0 International License (CC BY-NC-ND 4.0), which permits the non- 
commercial replication and distribution of the article with the strict proviso that no changes or edits are made and the original work is properly cited (including links to both the formal publication through the relevant DOI and the license). See: https://creativecommons.org/licenses/by-nc-nd/4.0/.

\section{References}

1. Wang D, Hu B, Hu C, et al. Clinical Characteristics of 138 Hospitalized Patients With 2019 Novel CoronavirusInfected Pneumonia in Wuhan, China. JAMA 2020;323:1061-9.

2. Huang $\mathrm{C}$, Wang $\mathrm{Y}, \mathrm{Li}$ X, et al. Clinical features of patients infected with 2019 novel coronavirus in Wuhan, China. Lancet 2020;395:497-506.

3. Lu R, Zhao X, Li J, et al. Genomic characterisation and epidemiology of 2019 novel coronavirus: implications for virus origins and receptor binding. Lancet 2020;395:565-74.

4. Channappanavar R, Perlman S. Pathogenic human coronavirus infections: causes and consequences of cytokine storm and immunopathology. Semin Immunopathol 2017;39:529-39.

5. Li XY, Sun B, Wang CT, et al. A follow-up study on acute respiratory distress syndrome survivors after extracorporeal membrane oxygenation by pulmonary high-resolution CT. Arch Iran Med 2015;18:6-11.

6. Venkataraman T, Frieman MB. The role of epidermal growth factor receptor (EGFR) signaling in SARS coronavirus-induced pulmonary fibrosis. Antiviral Res 2017;143:142-50.

7. Tian S, Hu W, Niu L, et al. Pulmonary Pathology of Early-Phase 2019 Novel Coronavirus (COVID-19) Pneumonia in Two Patients With Lung Cancer. J Thorac Oncol 2020;15:700-4.

8. Ye Z, Zhang Y, Wang Y, et al. Chest CT manifestations of new coronavirus disease 2019 (COVID-19): a pictorial review. Eur Radiol 2020;30:4381-9.

Cite this article as: Lv D, Chen X, Wang X, Mao L, Sun J, Wu G, Lin Z, Lin R, Yu J, Wu X, Jiang Y. Pulmonary function of patients with 2019 novel coronavirus induced-pneumonia: a retrospective cohort study. Ann Palliat Med 2020;9(5):3447-3452. doi: 10.21037/apm-20-1688
9. Lin L, Li TS. Interpretation of "Guidelines for the Diagnosis and Treatment of Novel Coronavirus (2019-nCoV) Infection by the National Health Commission (Trial Version 5)". Zhonghua Yi Xue Za Zhi 2020;100:805-7.

10. Standardization of Spirometry, 1994 Update. American Thoracic Society. Am J Respir Crit Care Med 1995;152:1107-36.

11. Ruuskanen O, Lahti E, Jennings LC, et al. Viral pneumonia. Lancet. 2011;377:1264-75.

12. Das KM, Lee EY, Al Jawder SE, et al. Acute Middle East Respiratory Syndrome Coronavirus: Temporal Lung Changes Observed on the Chest Radiographs of 55 Patients. AJR Am J Roentgenol 2015;205:W267-74.

13. Chen J, $\mathrm{Wu} \mathrm{J}$, Hao S, et al. Long term outcomes in survivors of epidemic Influenza A (H7N9) virus infection. Sci Rep 2017;7:17275.

14. Liu W, Peng L, Liu H, et al. Pulmonary Function and Clinical Manifestations of Patients Infected with Mild Influenza A Virus Subtype H1N1: A One-Year Follow-Up. PLoS One 2015;10:e0133698.

15. Mineo G, Ciccarese F, Modolon C, et al. Post-ARDS pulmonary fibrosis in patients with H1N1 pneumonia: role of follow-up CT. Radiol Med 2012;117:185-200.

16. Chan KS, Zheng JP, Mok YW, et al. SARS: prognosis, outcome and sequelae. Respirology 2003;8 Suppl:S36-S40.

17. Zhang P, Li J, Liu H, et al. Long-term bone and lung consequences associated with hospital-acquired severe acute respiratory syndrome: a 15 -year follow-up from a prospective cohort study. Bone Res 2020;8:8.

18. Li LF, Kao KC, Liu YY, et al. Nintedanib reduces ventilation-augmented bleomycin-induced epithelialmesenchymal transition and lung fibrosis through suppression of the Src pathway. J Cell Mol Med 2017;21:2937-49.

(English Language Editor: C. Betlazar-Maseh) 